\title{
Safety of Enteral Nutrition Practices: Overcoming the Contamination Challenges
}

\author{
Saswati Sinha ${ }^{1}$, Gunjan Lath², Sameer Rao ${ }^{3}$
}

\begin{abstract}
Enteral nutrition (EN) has host of benefits to offer to critically ill patients and is the preferred route of feeding over parenteral nutrition. But along with the many outcome benefits of enteral feeding come the potential for adverse effects that includes gastrointestinal (GI) disturbances mainly attributed to contaminated feeds. Currently, EN is practiced using blenderized/kitchen prepared feeds or scientifically developed commercial feeds. Commercial feeds based on their formulation may be divided as ready-to-mix powder formulas or ready-to-hang sterile liquid formulas. A holistic view on potential sterility of EN from preparation to patient delivery would be looked upon. These sterility issues may potentially result in clinical complications, and hence process-related errors need to be eliminated in hospital practice, since immunocompromised intensive care unit patients are at high risk of infection. This review intends to discuss the various EN practices, risk of contamination, and ways to overcome the same for better nutrition delivery to the patients. Among the various types of enteral formulas and delivery methods, this article tries to summarize several benefits and risks associated with each delivery system using the currently available literature.

Keywords: Blenderized feed, Closed system and open system, Enteral Nutrition, Ready-to-hang feeds.

Indian Journal of Critical Care Medicine (2020): 10.5005/jp-journals-10071-23530
\end{abstract}

\section{INTRODUCTION}

Enteral nutrition (EN) is the provision of nutrients via the gastrointestinal tract (through a feeding tube, catheter or stoma) and is the preferred route in patients who cannot meet their nutritional needs through voluntary oral intake. ${ }^{1}$ Unless there is any contraindication for enteral nutrition, EN is the preferred route of feeding over parenteral nutrition (PN) for the critically ill patients who require nutrition therapy as supported by current international guideline recommendations. ${ }^{2-5}$ Compared to PN, EN is associated with fewer infectious complications, reduced cost, earlier gut function, and reduced length of stay. ${ }^{6}$ Patients in the intensive care unit are at high risk of developing nosocomial infections. Studies suggest contaminated EN solutions represent a significant cause of nosocomial infections. ${ }^{7,8}$ Moreover, gastrointestinal disturbances are another frequently encountered complication that has been associated with bacterial contamination of the feed. ${ }^{9}$ Therefore, it is important to minimize bacterial contamination of enteral feeding to improve patient outcomes.

EN feeds are currently available as:

- Blenderized or kitchen prepared feeds

- Scientifically developed commercial feeds. These are mainly of 2 types:

- Powdered form that needs to be reconstituted

- Liquid or ready-to-hang

EN delivery systems are of 2 types:

- Open system (OS):This includes ready-to-use cans and powdered or sterilized formulas that require reconstitution with water. This system involves many manipulations, in terms of selection of ingredients, reconstitution of the mixture with water, storage or transport of the feed, transfer to the container, assembly of the feeding system, and finally administration of the feed. Recommended hang time for these mixtures is 4 hours. This system consumes more nursing time.
${ }^{1}$ Department of Critical Care, AMRI Hospital, Kolkata, West Bengal, India

${ }^{2,3}$ Department of Scientific and Medical Affairs, Abbott Nutrition International, Kolkata, West Bengal, India

Corresponding Author: Gunjan Lath, Department of Scientific and Medical Affairs, Abbott Nutrition International, Kolkata, West Bengal, India, Phone: +91 8017103170, e-mail: gunjan.lath@abbott.com

How to cite this article: Sinha S, Lath G, Rao S. Safety of Enteral Nutrition Practices: Overcoming the Contamination Challenges. Indian J Crit Care Med 2020;24(8):709-712.

Source of support: Nil

Conflict of interest: Gunjan Lath \& Sameer Rao are salaried employees of Abbott Nutrition International, India

- Closed system (CS) or ready-to-hang (RTH) system: This is a completely closed non-air-dependent collapsible bag system requiring minimal handling and minimal manipulations, with a recommended hang time of 24-48 hours. The ease of use associated with this system reduces nursing time and is also safe due to a minimal risk of contamination. ${ }^{10}$

This article will focus on the safety of currently used EN preparations and delivery methods.

\section{Materials and Methods}

Comprehensive, structured literature searches were conducted in PubMed and Google Scholar using key words enteral nutrition, blenderized feed, ready-to-hang feeds, and open and closed system enteral feeding. Subsequently, the relevant papers published till the year 2019 were fully reviewed, and their findings were noted.

(-) The Author(s). 2020 Open Access This article is distributed under the terms of the Creative Commons Attribution 4.0 International License (https://creativecommons. org/licenses/by-nc/4.0/), which permits unrestricted use, distribution, and non-commercial reproduction in any medium, provided you give appropriate credit to the original author(s) and the source, provide a link to the Creative Commons license, and indicate if changes were made. The Creative Commons Public Domain Dedication waiver (http://creativecommons.org/publicdomain/zero/1.0/) applies to the data made available in this article, unless otherwise stated. 


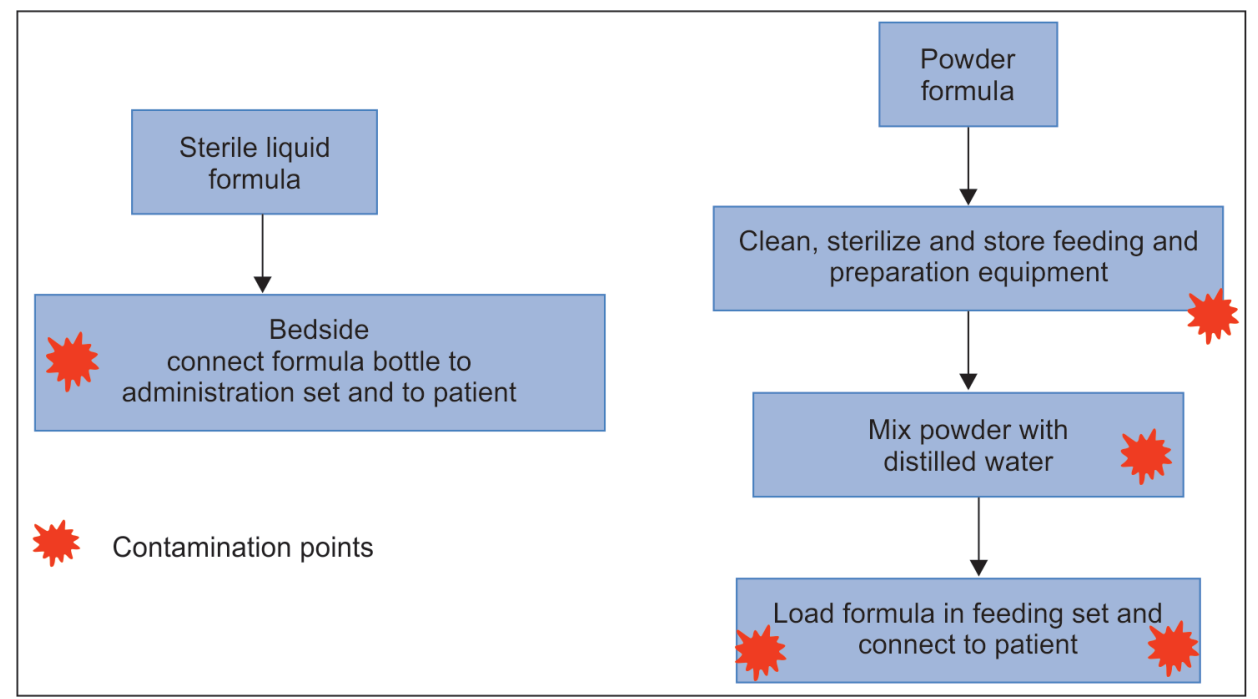

Fig. 1: Potential points for contamination during EN feeding process

\section{Enteral Feed Formulation and Microbiological Aspects}

Microbial contamination is one of the most important parameters for assessing the superiority of one type of EN over another. Blenderized tube feeding (BTF) formula is prepared in the kitchen by blending food or meals into a liquid feed. Hospital-prepared blenderized feedings made from natural foods show high levels of contamination. Maintaining the microbial quality of hospitalprepared blenderized feeds within the published standards of safety is difficult. Various factors responsible for bacterial contamination of handmade formulations include unhygienic original food items, food-making process and devices, blenders, hygiene of the floor and air-conditioning, environment of kitchen, negligence by kitchen staff/nurses, and food carriage process to the wards in a hot and humid conditions. ${ }^{12}$ While liquid enteral formulas are sterile since they undergo heat sterilization, powder formulas may not be sterile when packaged. Moreover, even if the powder formulas are manufactured in sterile conditions, extrinsic contamination may occur at the hands of the preparer or caregiver due to use of contaminated utensils, equipment, water and/or hands for manipulation, and preparation of the feed. ${ }^{12,13}$ Therefore, bacterial contamination of such prepared feeds from powder formulas tend to be cumulative, since it is related to the many manipulations of the feed and feeding systems between preparation and the end of administration. Compared to hospital-prepared feeds, ready-to-hang (RTH) formulas offer far fewer opportunities for contamination. When handled correctly, RTH formulas are virtually contamination free (Fig. 1). ${ }^{10,13}$

A randomized study analyzed quantitative factors, such as preparation time, waste, and contamination, associated with three different feeding systems for peptide-based diets: sterile closed system containers (CS) infused for more than 24 hours, open systems decanted from cans (OS-Can), and open systems mixed from powder (OS-Powder). Samples were taken for culture during preparation and after infusion. The study noted that preparation time was significantly shorter for CS than for OS-Can or for OS-Powder (2 minutes vs 7.5 minutes vs 13.0 minutes) and that bacterial contamination was the highest in the open delivery system. At baseline, $40 \%$ of the OS was significantly contaminated (>10,000 cfu/mL), while the CS showed no microbial growth. On final culture, significant contamination occurred in only $2 \%$ of the CS compared with $83 \%$ of the OS..$^{14}$ As per an in vitro study, when open and closed systems were compared in two long-term care facilities, high contamination $(>10,000 \mathrm{cfu} / \mathrm{mL}$ ) was found in $78 \%$ open samples compared with $39 \%$ from closed system ( $p$ value $<0.05) .^{15}$

Closed system provides host of benefits that include reduced risk of contamination and infection. However, even with closed system, certain protocols need to be followed. When handling closed system, it is important that the nurse wears sterile gloves, as contaminated hands could be a source of contamination. ${ }^{16}$ Closed systems tend to become contaminated, especially when manufacturer's instructions are not followed. ${ }^{17}$

Hanging time is another factor on which safety of enteral feeding depends. The length of time an enteral formula is considered safe for delivery to the patient beginning with the time the formula has either been reconstituted, warmed, and decanted or has had the original package seal broken. Hang time for BTF needs to be limited to 2 hours. Powder formulas once prepared should be ideally used within 4 hours of preparation. ${ }^{13}$ Sterile liquid RTH formulas offer increased hang times of up to 48 hours. However, most closed containers are discarded after 24 hours due to current manufacturer recommendations to change enteral feeding sets every 24 hours and to spike each closed container only once. Besides the feed, even the feeding delivery sets can be a source of contamination. Hence, they also need to be replaced every 24 hours (Table 1$){ }^{18}$

\section{Enteral Feed Formulation and Clinical Relevance}

Adequate nutrition plays a key role in the care of critically ill patients. In this regard, a study assessed the nutritional adequacy of EN feeds delivered via OS and CS in terms of the volume of feeds received by patients. The study noted that patients receiving formula through OS received an average of $74 \%$ of ordered volume and that patients receiving formula through CS received an average of $84 \%$ of ordered volume. ${ }^{19}$ 
Table 1: Comparison of various EN formulations

\begin{tabular}{|c|c|c|c|}
\hline Concern & Blenderized/kitchen prepared feeds & Ready-to-mix powder formulas & Ready-to-hang liquid formulas \\
\hline Contamination & Likely & Possible & Unlikely \\
\hline Consistent nutrient delivery & No & Depending on manipulation & Yes \\
\hline Preparation time & $\begin{array}{l}\text { Time consuming, need to procure } \\
\text { ingredients prior to preparing }\end{array}$ & $\begin{array}{l}\text { Less time consuming than blend- } \\
\text { erized feeds }\end{array}$ & $\begin{array}{l}\text { Least time consuming, saves } \\
\text { quality nursing time }\end{array}$ \\
\hline $\begin{array}{l}\text { Suitability for volume-sensitive } \\
\text { patients }\end{array}$ & $\begin{array}{l}\text { Hard to make high-density nutri- } \\
\text { tion }\end{array}$ & $\begin{array}{l}\text { Available at high-calorie densi- } \\
\text { ties but need to be mixed as per } \\
\text { instructions }\end{array}$ & Available at high-calorie densities \\
\hline Feeding tube flow & $\begin{array}{l}\text { Poor with gravity feeding; difficult } \\
\text { with pump propulsion; sieve to } \\
\text { lessen problems }\end{array}$ & Few or no flow problems & Few or no flow problems \\
\hline Hang time limits & $\begin{array}{l}\text { To be used within } 2 \text { hours once } \\
\text { prepared }\end{array}$ & $\begin{array}{l}\text { To be used within } 4 \text { hours of } \\
\text { powder mixed in water }\end{array}$ & $\begin{array}{l}\text { Can be used up to } 24 \text { hours once } \\
\text { opened }\end{array}$ \\
\hline
\end{tabular}

Contaminated enteral feeds is one of the factors that increase nosocomial infections and GI complications. ${ }^{7-9}$ Since closed system effectively reduces feed contamination, it does have an advantage over powder formulas in reducing infections.

Diarrhea and aspiration are two important and controversial complications in patients receiving enteral nutrition. There was significant association observed between the extent of bacterial contamination of enteral feeds and the incidence of diarrhea. ${ }^{20}$ Therefore, closed system would reduce the incidence of diarrhea. With regard to the risk of aspiration, rather than the type of EN formula being used, rate of feeding and feeding pattern is more important. Bolus feeds should be avoided. As such, closed system enteral feeds are hypercaloric formulas and are designed to be given by continuous feeding method.

Metabolic and electrolyte imbalances are another common complication associated with enteral feeding. Since RTH formulas are mostly hypercaloric, they tend to cause hypernatremia. This can be avoided by adjusting free water deficit and switching to distilled water from normal saline for flushing. Hyperglycemia may occur in critically ill patients if fed with high-calorie bolus feeds in addition to inappropriately low insulin or medication supplementation. All these clinical complications of enteral feeding including refeeding syndrome can be effectively managed provided our feeding method, rate, and pattern is appropriate. Often there is compromise on the way enteral feeding is administered, and then the EN formulas become the scapegoat.

\section{Enteral Feed Formulations and Cost and Nursing Time}

Management of OS system of EN consumed almost twice as much nursing time daily as $\mathrm{CS}^{21} \mathrm{~A}$ factor that needs to be considered would be the additional cost in changing over from the current formulations to RTH and closed systems. In the Western setting, studies have shown the cost of RTH formulas to be comparable to powder formulas when the cost of nursing time is factored in. ${ }^{22}$ However, we need to have such data from Indian perspective as well. In a scenario where healthcare expenditures are on the rise, cost might be a deterrent in widespread implementation of these systems, despite the definite advantages of enhanced nutrition delivery, decreased contamination risks, ease of use, longer hanging time, and saving nursing time. As experience with these RTH systems increase, there is likely to be a culture change in the prescription patterns of physicians, and the benefits these systems offer will definitely prove its worth.

\section{Guideline Recommendation on Enteral Feed Formulations}

All major guidelines including ASPEN and Indian Practice Guidelines recommend use of commercially produced, prefilled RTH feeds to be used wherever possible, as these are least likely to become contaminated during preparation and use. ${ }^{11,13}$ The guidelines highlight the benefit of using closed system formulations over open system and blenderized feeds.

\section{SUMMARY}

Contaminated enteral feeding systems may contribute to the etiology of nosocomial infections and GI disturbances. Since hospitalized patients and even critically ill patients receive these nutritional formulations, it may add to their morbidity. Appropriate measures during manipulation of enteral feeding that reduce the risk of contamination need to be adopted as a quality improvement initiative in order to make this intervention safe. EN formulas prepared in a kitchen or in a patient care unit are at higher risks of contamination. Therefore, nutritionally appropriate sterile RTH formulas should gradually replace powdered formulas because of superior benefits and better sterility and safety attributes.

\section{References}

1. American Society for Parenteral and Enteral Nutrition Board of Directors and Standards Committee, Teitelbaum D, Guenter P, Howell WH, Kochevar ME, Roth J, et al. Definition of terms, style, and conventions used in A.S.P.E.N. Guidelines and standards. Nutr Clin Pract 2005;20(2):281-285.

2. Dellinger RP, Levy MM, Rhodes A, Annane D, Gerlach H, Opal SM, et al. Surviving sepsis campaign: international guidelines for management of severe sepsis and septic shock: 2012. Crit Care Med 2013;41(2):580-637.

3. Dhaliwal R, Cahill N, Lemieux M, Heyland DK. The canadian critical care nutrition guidelines in 2013: AN update on current recommendations and implementation strategies. Nutr Clin Pract 2014;29(1):29-43.

4. McClave S, Martindale R, Vanek V, McCarthy M, Roberts P, Taylor B, et al. Guidelines for the provision and assessment of nutrition support therapy in the adult critically ill patient: society of ritical care medicine (SCCM) and american society for parenteral and enteral nutrition (A.S.P.E.N.). JPEN J Parenter Enteral Nutr 2016;40(2):159-211.

5. Singer $P$, Berger MM, Van den Berghe $G$, Biolo $G$, Calder $P$, Forbes $A$, et al. ESPEN guidelines on parenteral nutrition: intensive care. Clin Nutr 2009;28(4):387-400.

6. Seres DS, Valcarcel M, Guillaume A. Advantages of enteral nutrition over parenteral nutrition. Therap Adv Gastroenterol 2013;6(2): 157-167. 
7. Fernandez-Crehuet Navajas M, Jurado Chacon D, Guillen Solvas JF, Galvez Vargas R. Bacterial contamination of enteral feeds as a possible risk of nosocomial infection. J Hosp Infect 1992;21(2):111-120.

8. Levy J, Van Laethem Y, Verhaegen G, Perpete C, Butzlet JP, Wenzel RP. Contaminated enteral nutrition solutions as a cause of nosocomial bloodstream infection: a study using plasmid fingerprinting. JPEN J Parenter Enteral Nutr 1989;13(3):228-234.

9. Kohn CL, Keithley JK. Enteral nutrition. potential complications and patient monitoring. Nurs Clin North Am 1989;24(2):339-353.

10. Sewify K, Genena D. Open vs closed tube feeding in critically ill patients-which is the best? J Nutr Food Sci 2017;7:621. DOl: 10.4172/2155-9600.1000621.

11. Mehta Y, Sunavala JD, Zirpe K, Tyagi N, Garg S, Sinha S, et al. practice guidelines for nutrition in critically ill patients: a relook for indian scenario. Indian J Crit Care Med 2018;22(4):263-273.

12. FAO. Enterobacter sakazakii and Other Microorganisms in Powdered Infant Formula. Rome, Italy: Food and Agriculture Organization of the United Nations; 2007. p. 81.

13. Boullata Jl, Carrera AL, Harvey L, Escuro AA, Hudson L, Mays A, et al. ASPEN safe practices for enteral nutrition therapy. JPEN J Parenter Enteral Nutr 2017;41(1):15-103.

14. Wagner DR, Elmore MF, Knoll DM. Evaluation of "closed" vs "open" systems for the delivery of peptide-based enteral diets. JPEN J Parenter Enteral Nutr 1994;18(5):453-457.
15. Herlick SJ, Vogt C, Pangman V, Fallis W. Comparison of open vs closed systems of intermittent enteral feeding in two long-term care facilities. Nutr Clinical Pract 2000;15(6):287-298.

16. Anderton A, Aidoo KE. Decanting - source of contamination of enteral feeds? Clin Nutr 1990;9(3):157-162.

17. Beattie TK, Anderton A. Microbiological evaluation of four enteral feeding systems which have been deliberately subjected to faulty handling procedures. J Hosp Infect 1999;42(1):11-20.

18. Arevalo-Manso JJ, Martinez-Sanchez P, Juares-Martin B, Fuentes B, Ruiz-Ares G, Sanz-Cuesta BE, et al. Preventing diarrhea in enteral nutrition: the impact of the delivery set hang time. Int J Clin Pract 2015;69(8):900-908.

19. Atkins A, Phillips W. Delivery of enteral nutrition improves after transition to a closed feeding system. Med Surg Mat 2015;24: 14-15.

20. Okuma T, Nakamura M, Totake H, Fukunaga Y. Microbial contamination of enteral feeding formulas and diarrhea. Nutrition 2000;16(9): 719-722.

21. Luther H, Barco K, Chima C, Yowler CJ. Comparative study of two systems of delivering supplemental protein with standardized tube feedings. J Burn Care Rehabil 2003;24(3):167-172.

22. Phillips W, Roman B, Glassman K. Economic impact of switching from an open to a closed enteral nutrition feeding system in an acute care setting. Nutr Clin Pract 2013;28(4):510-514. 